\title{
Simplified Equations for Calculation of Highly Potent Intravenous Drug Infusion with Confidence- A Review Article
}

\author{
Azad $\mathrm{AK}^{1}$, Ahsan $\mathrm{MN}^{2}$, Chowdhury DKP ${ }^{3}$, Rahman $\mathrm{A}^{4}$
}

\begin{abstract}
There are possibilities of potential hazards, as intravenous medications get rapid access to patient's circulatory system. Calculating and applying drugs as per order of physician is complex because there are so many factors have to be taken into account. Regardless of the drug to be administered, careful and accurate calculations are important to avoid medication errors. Practicing drug calculation as per equations described in this article will minimize errors and maximize confidence among healthcare professionals.
\end{abstract}

\section{Introduction}

"Doctors pour drugs of which they know little, to cure diseases of which they know less, into human beings of whom they know nothing ${ }^{1 .}$ "

\footnotetext{
--Voltaire--

Intravenous administration of medication supplies and distributes drug rapidly into patient's circulatory system, which might produces potential hazards. Errors in medication, dose, or dosage strength can be fatal. So, caution must be taken in the calculation, preparation, and administration of IV medications ${ }^{2,3}$. Many healthcare professionals and nurses have difficulty with drug calculations because they don't enjoy or understand math. Practicing drug calculations will help healthcare professionals and nurses to be stronger and confident in basic math skills. Many drugs require some type of calculation before administration. Complexity of drug calculation ranges from simple conversion calculation to a more complex calculation for drugs administered by $\mathrm{mcg} / \mathrm{kg} / \mathrm{min}$. Irrespective of the drug to be administered, careful and accurate calculations are important to help prevent medication errors ${ }^{4,5}$.
}

Aim : The aim of this article is to reduce incidence of drug calculation related errors and to provide simple equations and instructions for healthcare professionals.

Complexity of calculating drug dose: Various factors contribute to the complexity ${ }^{6,7,8}$.

1. Different requirements of healthcare professional and nurses concerned in the administration of infusion.

2. The relation between drug dosage rate and volume is confused by complicated expressions of concentration-percentage ( $\mathrm{vol} / \mathrm{vol}$, wt/vol), parts per thousand, parts per mille (\%), mass or mole per 100 $\mathrm{ml}$, per litre or per $\mathrm{ml}$.

3. Infusions necessarily require optimizing intake of liquid which might contribute appreciably to the patient's total intake especially children.

Complexity starts right from ordering the drug dose like dopamine $5 \mathrm{mcg} / \mathrm{kg} / \mathrm{min}$, for the dopamine order described above, here's how this equation would look for a patient who weight $70 \mathrm{kgs}^{9,10,11}$ :

$5 \mathrm{mcg} \times 70 \mathrm{~kg} \times 1 \mathrm{mg} / 1000 \mathrm{mcg} \times 60$ minutes $/ 1$ hour $\times 250 \mathrm{ml} / 800 \mathrm{mg}=6.56 \mathrm{ml} /$ hour.

But many nurses have trouble remembering what goes where-and in what order. Which goes on top- milligrams or micrograms? Hours or minutes? Milliliters or milligrams? Moreover, complexity deepen further when there are variations of order like $\mathrm{mcg} / \mathrm{kg} / \mathrm{min}, \mathrm{mcg} / \mathrm{kg} / \mathrm{hr}, \mathrm{mg} / \mathrm{kg}$, unit $/ \mathrm{km} / \mathrm{min}$, drip factor etc and variation of drug dose between children and adult, and on availability of flow control device.

1. Lt Col Abul Kalam Azad, MBBS, DA, FCPS, Classified Spl in Anaesthesiology, CMH, Dhaka; 2. Brig Gen Md Nazmul Ahsan, MBBS, FCPS, Adviser Anaesthesiologist, CMH, Dhaka; 3. Col Dipak Kumer Paul Chowdhury, MBBS, M.Phil, Instructor of Pharmacology, AFMI, Dhaka; 4. Lt Col Aminur Rahman, MBBS, DA, FCPS, Classified Spl in Anaesthesiologist, $\mathrm{CMH}$, Dhaka. 
Commonly used abbreviations \& basic math: Many trusts' drug policies state that certain abbreviations should not be used in prescriptions because they are a source of errors if misunderstood ${ }^{12-16}$.

\begin{tabular}{|l|l|}
\hline Unit & Usually accepted abbreviations \\
\hline Kilogram & $\mathrm{kg}$ \\
Milligram & $\mathrm{gm}$ \\
Microgram & $\mathrm{mg}$ \\
Nanogram & should always be written as microgram (mcg or $\mu \mathrm{g})$ \\
Litre & should always be written as nanogram (ng) \\
Milliliter & $\mathrm{L}$ \\
Units or international units & $\mathrm{ml}$ or mL \\
Millimoles & should always be written as units or international units \\
Drops & $\mathrm{mmol}$ or mMol \\
\hline
\end{tabular}

Metric System ${ }^{17}$

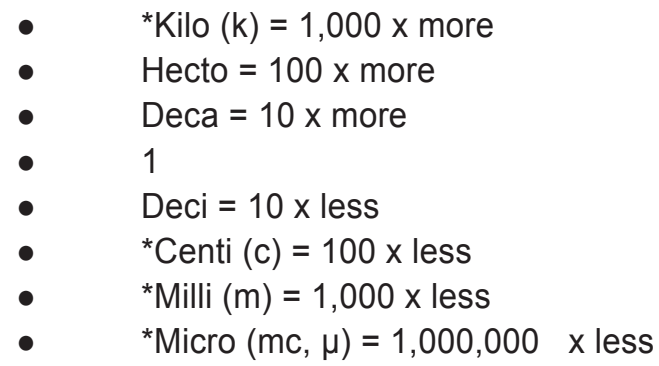

Metric Style of Notation ${ }^{17}$

- $\quad$ Units not capitalized (gram, not Gram)

- $\quad$ Periods not used with unit abbreviations (mL, not m.L. or $\mathrm{mL}$.)

- $\quad$ Single space between quantity and symbol $(24 \mathrm{~kg}$, not $24 \mathrm{~kg})$

- $\quad$ Abbreviations are not pluralized ( $\mathrm{kg}$, not $\mathrm{kgs})$

- $\quad$ Fractions should not be used, only decimal notation $(0.25 \mathrm{~kg}$, not $1 / 4 \mathrm{~kg})$

- $\quad$ Quantities less than 1 should have a 0 placed to the left of the decimal point $(0.75 \mathrm{mg}$, not $.75 \mathrm{mg})$

Conversion: ${ }^{18}$

- Convert grams to milligrams: multiply X 1000

- Convert liters to milliliters: multiply X1000

- Convert milligrams to grams: divide by 1000

- Convert milliliters to liters: divide by 1000

Calculating concentrations ${ }^{12-16}$ :

The way the strength of a drug in a solution is described will affect the way a dose calculation is carried out. 
Doses may be expressed in a number of different ways:

- Mass (weight) per volume of solution e.g. $\mathrm{mg}$ in $10 \mathrm{ml}, \mathrm{mMol} / \mathrm{L}$.

- Units of activity per volume of solution e.g. units per $\mathrm{ml}$.

- Percentage: This is the weight of the drug in grams that is contained in each $100 \mathrm{ml}$ of the solution.

- Ratio: 1 in 1000 solution of adrenaline contains $1 \mathrm{~g}$ in $1000 \mathrm{ml}=1000 \mathrm{mg}$ in $1000 \mathrm{ml}=1 \mathrm{mg}$ in $1 \mathrm{ml}$

1 in 10,000 solution of adrenaline contains $1 \mathrm{~g}$ in $10,000 \mathrm{ml}=1000 \mathrm{mg}$ in $10,000 \mathrm{ml}=1 \mathrm{mg}$ in $10 \mathrm{ml}$

Remember ${ }^{12-16}$ :

- If you know the number of grams in $1000 \mathrm{ml}$, divide by 10 to convert to $\%$ strength.

- If you know the \% strength, multiply by 10 to give the number of grams of drug in $1000 \mathrm{ml}$.

- If you know the \% strength, divide by 100 to calculate the amount of drug in $1 \mathrm{ml}$.

\section{Common errors}

Definition of medication error ${ }^{19,20,21}$ : An error in prescribing, dispensing or administering of a drug, irrespective of whether such errors lead to adverse consequences or not.

\section{Procedural failures ${ }^{22}$}

- $\quad$ Failure to read medication label

- $\quad$ Failure to check patient identification (Failure of nurse to check the patient's identification)

- $\quad$ Temporary storage of medication in unsecure environment, for example at the nurses' station

- $\quad$ Failure to record medication administration on medication chart

- Non-aseptic technique (observation of gross breaches of aseptic technique e.g., not washing hands before preparation of injection)

- $\quad$ Failure to check pulse/blood pressure before administration (when applicable)

- $\quad$ Failure to check blood sugar level prior to administering insulin

- $\quad$ Failure of two nurses to sign the dangerous drug register (applicable for dangerous drugs ${ }^{*}$ )

- If intravenous medication:

- - Failure of two nurses to check preparation

- - Failure of two nurses to witness administration of a dangerous drug

- Failure of two nurses to sign medication chart (applicable for dangerous drugs)

\section{Clinical intravenous errors ${ }^{22}$}

- Wrong intravenous rate: administration of intravenous drug at a faster rate than recommended.

- Wrong mixture: use of a solvent/diluents/additive that was incorrect according to protocol.

- Wrong volume: using a volume of diluents/solvent to prepare an injectable medication that differs from the protocol.

- Drug incompatibility: one drug given with another drug or solution via the same intravenous infusion, or same bag, which is NOT documented to be compatible. For example: frusemide and cefotaxime administered in combination.

Error preventive strategies ${ }^{23}$ : To prevent medication error and effectively ensure safe patient treatment it is important to combine product and organizational measures.

Safe practice recommendations: Healthcare organizations should consider the following suggestions to reduce the risk of IV dosing errors:

- Standardize dosing methods: Look for variable dosing methods for the same medication in your hospital, and select a standard way to dose the drug for adults and a standard way to dose the drug for paediatric patients. Also examine the different dosing methods used in the organization for all drugs, and to the extent possible, standardize the dosing methods to promote familiarity. Health systems comprising multiple hospitals will also benefit from system-level standardization, as patients and nurses may transfer among the facilities. 
- Use fully functional smart pumps: Use of smart pumps that provide dosage error-reduction software will help avoid harmful mix-ups among various dosing methods for the drugs in the pump's library. Other safety features include unchangeable dosing units once a drug is selected, weight limits, and clinical advisories. Smart pump alerts warn practitioners of impending medication errors and should not be overridden. If an alert is activated, it is crucial for the practitioner to investigate the warning and act accordingly. Organizations should conduct regular compliance rounds to ensure that the dose-checking capabilities are fully functional, as well as review available data from the error-reduction software to monitor appropriate staff interaction with the technology.

- List dosing methods on MARs and labels: When possible, the dose of a medication should be displayed on the medication administration record (MAR) and the drug container label the same way the information will be needed to program the pump.

- List dosing methods on orders: Prescribers should list the dosing method used along with the calculated dose of drugs at risk for error (e.g., paediatric drugs, chemotherapy).

- Verify the dosing method: When applicable, pharmacists and nurses should verify both the dosing method used and the calculated dose before dispensing or administering a medication.

- Verify pump settings during hand-offs: Verify all pump settings upon transfer of patients and at the beginning of each shift. Be sure the dosing method and total dose make sense for the patient given his or her weight, age, and condition.

- Suspect an error: If a patient is not exhibiting the physiologic changes that would be expected given the infusion, consider the possibility of an error, and verify the pump settings.

- Use simulation training: To heighten staff awareness about mix-ups with dosing methods, consider simulation training in which participants investigate a hypothetical case with a dosing error, uncover the error, and take corrective action.

Moreover, there are 9 "Rights" of effective prevention ${ }^{19}$ :

- $\quad$ Right patient

- $\quad$ Right drug

- Right route

- Right time

- Right dose

- Right documentation

- Right action

- $\quad$ Right form

- $\quad$ Right response

\section{Equations for intravenous infusion:}

\section{Simpler is better ${ }^{9,10,11}$}

Equation ${ }^{9,10,11}: 1$

Remember: Before doing the calculation, convert units of measurement into one system.

$$
\text { IV infusion } \operatorname{rate}\left(\frac{\mathrm{ml}}{\mathrm{hr}}\right)=\frac{\text { Ordered amount of drug } \times \mathrm{Wt} \text { in } \mathrm{kg} \times 60}{\operatorname{Drug} \operatorname{conc}\left(\frac{\mathrm{mg}}{\mathrm{ml}}\right)}
$$


Here's what each element in the simplified equation represents:

- $\quad$ Amount of drug ordered like $\mathrm{mcg} / \mathrm{kg} / \mathrm{min}, \mathrm{mg} / \mathrm{kg} / \mathrm{min}$ or $\mathrm{mcg} / \mathrm{kg} / \mathrm{hr}$ etc

- $\quad$ Patient's weight in $\mathrm{kg}$

- $\quad$ Concentrations of drug in each $\mathrm{ml}$

- 60 refers to 60 minutes/hour (although the order is written in $\mathrm{mcg} / \mathrm{kg} / \mathrm{minute}$, the pump runs in $\mathrm{ml} / \mathrm{hour}$ )

Equation $^{24,25,26,27,28}: 2$

REMEMBER: ALWAYS WORK THE EQUATION BACKWARDS AGAIN TO DOUBLE CHECK YOUR MATH!

Lester's No-Math Rule for Intravenous Infusions: The number of milligrams in $250 \mathrm{~mL}$ comes out in micrograms in one minute at a setting of $15 \mathrm{~mL} / \mathrm{hr}$ and The number of grams in $250 \mathrm{~mL}$ comes out in milligrams in one minute at a setting of $15 \mathrm{~mL} / \mathrm{hr}$.

\section{Explanation}

1. The basis for this is, that at a setting of $15 \mathrm{~mL} / \mathrm{hr}$, the delivered volume per minute is $0.25 \mathrm{~mL}$

2. Why does this work? $0.25 \mathrm{~mL}$ is $1 / 1,000$ of the volume in a $250 \mathrm{~mL}$ intravenous bag. Therefore it contains $1 / 1,000$ of the mass of drug in the IV solution.

3. $1 \mathrm{mcg}$ is 0.001 of $1 \mathrm{mg}$ (and $1 \mathrm{mg}$ is 0.001 of $1 \mathrm{gm}$ ). Therefore, (as Lester states), the number of milligrams in $250 \mathrm{~mL}$ comes out in micrograms in one minute at a setting of $15 \mathrm{~mL} / \mathrm{hr}$.

Equation $^{29,30}: 3$

The formula Rule of 6 had been stated in The Harriet Lane Handbook is as follows:

" $6 \times$ weight $(\mathrm{kg})$ equals the amount of drug in $\mathrm{mg}$ that should be added to $100 \mathrm{ml}$ of solution. The infusion volume in milliliters per hour ( $\mathrm{ml} /$ hour) will then equal the $\mathrm{mcg} / \mathrm{kg} /$ minute dose ordered."

Explanation $^{31}$

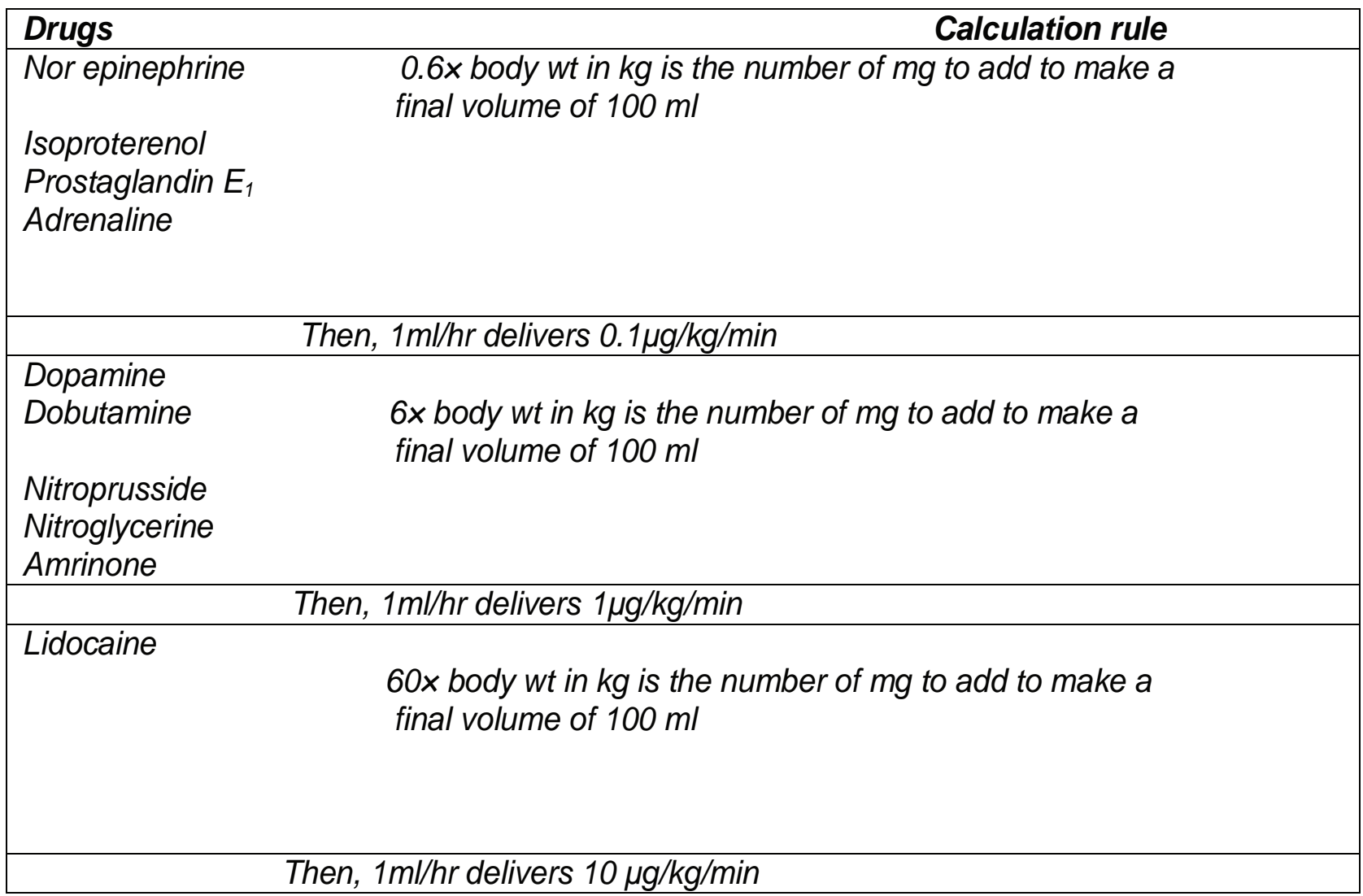


Mnemonic: NIPA $\mathrm{D}_{2} \mathrm{~N}_{2} \mathrm{~A}$ Long

\section{Critiques of different equations:}

Equation $^{9,10,11}-1$ :

Before using this simplified equation, you must perform a conversion to find the drug concentration when the order is written in micrograms but the drug is available as milligrams in milliliters of solution. Fortunately, this conversion is simple. Multiply the available milligrams by $1000(1 \mathrm{mg}=1,000 \mathrm{mcg})$ and then divide the result by the amount of solution.

Equation $^{24,25,26,27,28}-2$ :

Need to know basic math skill

Equation ${ }^{29,30}-3$ :

1. Paediatric drug solutions that have been prepared using the rule of 6 can result in fluid overload when dose adjustments are necessary.

2. In some facilities or settings, the rule of 6 is not followed consistently. Some practitioners use it; others don't. Thus, physicians or nurses who consistently use the rule of 6 might assume that all solutions dosed in $\mathrm{mcg} / \mathrm{kg} /$ minute are prepared in this fashion. However, if a solution with a different concentration is used, these practitioners might adjust rates inaccurately.

3. The rule of 6 requires that critical-care drug doses be calculated mathematically. This calculation process is always prone to error. Mistakes have been reported when nurses confuse "mg" with "ml" and add the drug to the solution by volume rather than by weight (e.g., adding $30 \mathrm{ml}$ instead of $30 \mathrm{mg}$ ). Ensuring accurate pump settings can also be problematic if " $\mathrm{ml} /$ hour" is con-fused with "ml/24 hours."

4. Finally, use of the rule of 6 results in drug waste. The amount needed to prepare solutions in this manner is usually only a portion of the drug vial. Either the remaining drug is wasted, or single-dose containers are reused inappropriately.

\section{Conclusion $^{29,30}$}

Simplification and standardization can reduce the potential for errors. The use of standardized concentrations of critical care drugs and corresponding dosing charts, dose in $\mathrm{mcg} / \mathrm{kg} /$ minute, can help simplify the process by preventing errors prone calculations, by avoiding the use of the wrong diluents or volume, by reducing the number of discarded doses and necessary dose preparations, and by facilitating the use of pre-mixed IV solutions.

\section{References}

1. IV infusions and drug calculations made easy (Really). Drug calculations student handout version. Web: http://www.api.ning.com/files/ck8.

2. Calculating flow rates for intravenous medications. Web:http://www.health.prenhall.com/olsen/pdf/olsen ch11.pdf

3. Media Link. Calculating flow rates for intravenous medications. Web: http://www.prenhall.com/olsen ch6-9.pdf

4. Brush up on Your Drug Calculation Skill. Web: http://www.nursesaregreat.com/articles/drugcal.htm

5. Springhouse PC. Dosage Calculations Made Incredibly Easy! http://www.alibris.com/booksearch? qwork=8821100.

6. R J Brooks, A M Wilson. Simplifying infusion calculations. Br Med J 1985;290:291-2.

7. Calculating intravenous medications. Crit Care Nurse.1982 Sep-Oct;2(5):92-4.

8. Dc Angelis R, Brott WH. Converting microdrop $/ \mathrm{kg} / \mathrm{min}$ to microdrops. The ' Factor of 15 ' method. Crit Care Nurse1982 Nov-Dec;1(6):334-7.

9. Ira Gene Reynolds. Calculating IV drip rates with confidence-American Nurse today. Web:http://www. americannursetoday.com/..../0d39b2a0e79043daa93 d229d73cf4...

10. Ira Gene Reynolds. Calculating IV drip rates with confidence-American Nurse today. Web: http://www. americannursetoday.com/Article. aspx? $\mathrm{id}=6208 \& \mathrm{fid} . .$.

11. Guide to calculation IV drip rates/Prophecy Healthcare. Web: http://www.prophecyhealthcare.com $>$ Prophecyhealthcare.

12. Good practice for drug calculations. Baxter UK. http://www.baxterhealthcare.co.uk/downloads/.../ps_ calc_guide.pdf 
13. Multi-professional safer practice standards for: prescribing, preparing and administering injectable medicines in clinical areas. Patient Safety Alert 20: Promoting Safer Use of Injectable Medicines, The National Patient Safety Agency, 28 March 2007.

14. Safety in doses: improving the use of medicines in the NHS, The National Patient Safety Agency, 2007, p19.

15. Sarpal, N (2008) Drug administration: delivery (infusion devices) in The Royal Marsden Hospital Manual of Clinical Nursing Procedures edited by Dougherty, L \& Lister, S, 7th Edition, Wiley Blackwell, chapter 13, page 302.

16. Lapham $\mathrm{R} \&$ Agar $\mathrm{H}$. Drug calculation for nurses: A step by step Approach 2nd edition Hodder Arnold, London 2003.

17. Pharmacological and fluid infusions. IV infusions and drug calculation made easy. Web: http://www.api. ning.com/.../DrugCalculationsStudenthandoutversion.ppt

18. Kent R. Spiter. IV and drug calculations for busy paramedics-GAEMS.net Web: http://www. gaems.net/ download/drugcalc.pdf

19. Medication error-B.Braun Medical SA. Web: http://www.francais.bbraun.ch/.../Content_Wissen_Risi kopraevention_Inf...

20. Medication error prevention toolbox- Institute for safe Medication... Web: http://www.ispm.org/msaarticles/toolbox.htm

21. Medication Error Prevention. Web: http:// www.medscape.org/veiwarticles/550273.
22. Johanna I Westbrook, Marilyn I Rob, Amanda Woods, Dave Parry. Errors in the administration of intravenous medications in hospital and the role of correct procedures and nurse experience. BMJ Quality \& Safety2011;101136/bmjqs-2011-000089.

23. Medication Safety Alert/Lack of Standard dosing methods contributes to IV errors. Web: http://www. ismp.org/newsletters/acutecare/articles/2007082.asp

24. Clinical Mathematics. Web: http://www. udmercy. edu/crna/agm/mathweb09.pdf

25. Waugaman et al. Nurse Anesthesia 2nd ed. Chapter 4 on Metric medical mathematics by Marian Waterhouse. ISBN 0-8385-7962-0 1992 Appleton Lange.

26. Kee JL, Marshall SM. Clinical Calculations. 2nd ed. Philadelphia: WB Saunders; 1992 (or newer editions).

27. Drug Calculations for Health professionals- Quiz page. http://www.testandcalc.com/quiz/index.asp

28. Shubert D, Leyba J. Chemistry and physics for nurse anesthesia. New York: Springer; 2009.

29. "Rule of 6" not optimal for patient safety. Web: http://www.pharmscope.com/ptJournal/dl.cfm?file=fu lltext/28/4/.....

30. The rule of six in drug dosing and infusion-Emergency medicine. Web: http://www. emergencymedic.blogpot.com/...../rule-of-six-in-drug -dosing...

31. Shoemaker. Textbook of Critical Care, 4th edition; Saunders, 2000:1123. 